\title{
Qual é o real valor da dosagem da hemoglobina glicada (A1C)?
}

O ensaio da hemoglobina glicada (A1C) tem sido considerado o padrão-ouro na avaliação do controle glicêmico de pacientes com diabetes. Constitui um preditor das complicações crônicas da moléstia, sendo que intervenções que acarretam redução ou normalização da A1C resultam em diminuição do risco de desenvolvimento de tais complicações, conforme demonstrado pelos estudos Diabetes Control and Complications Trial (DCCT) e United Kingdom Prospective Diabetes Study (UKPDS) $)^{(1,2,3)}$. O seu uso prático tem sido extremamente difundido, tornando-se quase indispensável na prática clínica. É um marcador do bom ou mau controle do diabetes e, de maneira geral, reflete os níveis glicêmicos dos últimos três meses.

Esta edição do Jornal Brasileiro de Patologia e Medicina Laboratorial (JBPML) apresenta um artigo de revisão sobre a importância da determinação da A1C no monitoramento das complicacões crônicas do diabetes ${ }^{(4)}$. Em apresentação bastante didática, o artigo de Andriolo e Sumita tece consideracões sobre a importância da $\mathrm{A} 1 \mathrm{C}$ no controle do diabetes, da padronização dos diferentes métodos de dosagem e comenta os aspectos laboratoriais. Além disso, discute as metas a serem alcançadas nos níveis de A1C, assim como a freqüência com que as determinações devem ser realizadas (duas vezes ao ano e/ou, quando houver mudança do esquema terapêutico, trimestralmente). A meta a ser atingida é de $7 \%$ no adulto. Em populações especiais, como idosos e crianças, 0 alvo pode ser ajustado em razão do risco de hipoglicemia.

Também mencionam a importante recomendação para que os laboratórios clínicos utilizem apenas ensaios certificados pelo National Glycohemoglobin Standardization Program (NCSP), com rastreabilidade de desempenho analítico ao método utilizado no DCCT. Esse fato é de fundamental importância para reduzir a enorme variabilidade interlaboratorial e possibilitar uma melhora acentuada na precisão dos valores obtidos ${ }^{(5)}$. Realmente, clínicos e pacientes sentem dificuldade em interpretar dados laboratoriais, muitas vezes discrepantes, e transferi-los para ações que resultem em mudanças de esquemas de tratamento.

Apesar dos esforços para padronização dos métodos, ainda é elevado o número de médicos que não solicitam o teste e de pacientes que desconhecem esse exame. Obviamente a grande maioria está mais familiarizada com os níveis de glicemia expressos em $\mathrm{mg} / \mathrm{dll}$, e não com a percentagem de glicação da hemoglobina, tornando difícil a compreensão exata do que realmente expressa o exame laboratorial da A1C. E necessário esclarecer que não é exatamente a "média das glicemias dos últimos três meses", conforme usualmente é referido, mas sim outro parâmetro que expressa o "controle dos últimos três meses", o qual é definido em percentual e não em $\mathrm{mg} / \mathrm{dl}$.

O artigo de Andriolo e Sumita traz ainda uma atualização importante quando mencionam em "Novos conceitos e tendências" a correlação da A1C com a glicemia média. O resultado da glicemia média estimada pode ser obtido mediante uma equação matemática. Os autores recomendam que o laudo da A1C venha acompanhado do resultado da glicemia média estimada. Esse procedimento, sem dúvida, facilitaria enormemente a interpretação clínica da A1C.

O diabetes é uma moléstia em que o paciente participa ativamente do seu tratamento. Contudo, o resultado da glicemia média estimada acarretaria uma melhor compreensão para o paciente do que realmente o teste da A1C está expressando. A fórmula para cálculo da glicemia média estimada é a seguinte: $28,7 \times A 1 C$ - 46.7 .

A American Diabetes Association (ADA) disponibiliza no site www.diabetes.org/professional/eAG a possibilidade de se obter, a partir da A1C, os valores da glicemia média estimada (GME) e vice-versa. Um fato conhecido, que é a base fundamental para o emprego da A1C como parâmetro de controle do diabetes, seria a correlação positiva da A1C com a GME. A A1C e a GME representam a mesma coisa, ou seja, o quanto de glicose mais elevada ou não existe no organismo. Simplesmente deixa a compreensão mais fácil. Assim, uma A1C de 7\% corresponde a uma GME de $154 \mathrm{mg} / \mathrm{dl}$, expressando o grau de controle do diabetes nas mesmas unidades a que o paciente e clínicos gerais estão habituados, principalmente com o uso disseminado e crescente resultante do monitoramento domiciliar da glicose por meio de medidas obtidas com o emprego dos glicosímetros.

Recentemente foi publicado com grande repercussão o estudo Derived Average Glucose (ADAG)(6), que foi patrocinado por três grandes organizações da área de diabetes: International Diabetes Federation (IDF), ADA e a European Association for the Study of Diabetes (EASD). O ADAG foi conduzido em resposta a um novo método de padronização do ensaio da hemoglobina glicada, que resultou em valores entre $1,5 \%$ e $2 \%$ mais baixos que os padrões atuais, o que pode causar considerável confusão em pacientes, médicos e educadores em diabetes.

O objetivo do estudo ADAG foi definir a relação matemática entre a A1C e a GME para determinar se a A1C poderia, de forma confiável, ser expressa nas mesmas unidades utilizadas no automonitoramento da glicose $(\mathrm{mg} / \mathrm{dl})$.

É obvio que há uma correlacão entre os valores da A1C e a GME, mas isso só foi efetivamente demonstrado com o estudo ADAG. Por outro lado, é importante lembrar que a variabilidade dos níveis glicêmicos e as oscilações da glicose podem ser mais deletérias para a função endotelial do que a glicose media estimada(7,8).

Portanto, é possível relatar os valores da A1C nas mesmas unidades utilizadas para o automonitoramento, isto é em $\mathrm{mg} / \mathrm{dl}$.

É importante lembrar que a GME não é exatamente a média dos valores de glicose obtidos com o glicosímetro, visto que a maioria dos pacientes testa a glicose um número de vezes bem menor em relação ao que poderia representar a média da glicose durante 24 horas, incluindo os períodos pós-prandiais em que os pacientes são menos propensos a realizar o teste.

Realmente, o estudo ADAG utilizou várias medidas durante o dia, além dos valores obtidos com o uso do Continuous Glucose Monitoring System (CGMS). A IDF, ADA e a EASD estão trabalhando de forma integrada a fim de encorajar o acoplamento dos resultados da GME com os da A1C.

Para concluir, entre o médico e o paciente realmente deve haver números (A1C e GME) que possam efetivamente traduzir em notas o grau de controle do paciente, conscientizando-o a melhorar sempre o seu grau de controle glicêmico, uma vez que desse controle depende a prevenção das complicações crônicas da doença.

Embora não cite o estudo ADAG, o artigo de revisão de Andriolo e Sumita difunde de maneira extremamente didática a importância da hemoglobina glicada no controle do diabetes e na avaliação de risco das complicações crônicas.

\section{Dr. Antonio Roberto Chacra}

Professor titular e chefe da Disciplina de Endocrinologia da Universidade Federal de São Paulo (UNIFESP)

\section{Referências}

1. DIABETES CONTROL AND COMPLICATIONS TRIAL RESEARCH GROUP. The effect of intensive diabetes treatment on the development and progression of long-term complications in insulin-dependent diabetes mellitus: Diabetes Control and Complications Trial. N Engl J Med, v. 329, p. 978-86, 1993.

2. DIABETES CONTROL AND COMPLICATIONS TRIAL RESEARCH GROUP. The association between glycaemic exposure and long-term diabetic complications in the Diabetes Control and Complications Trial. Diabetes, v. 44, p. 968-83, 1995.

3. UK PROSPECTIVE DIABETES STUDY GROUP. Intensive blood-glucose control with sulphynylureas or insulin compared with conventional treatment and risk of complications in patients with type 2 diabetes (UKPDS 33). Lancet, v. 352, p. 837-53, 1988.

4. ANDRIOLO, A.; SUMITA, N. M. Importância da hemoglobina glicada no controle do diabetes mellitus e na avaliação de risco das complicações crônicas. JBPML, v. 44, n. 3 , p. $169-174,2008$

5. LITTLE, R. R.; GOLDSTEIN, D.E. Endocrine standardizations of glucohemoglobin measurements. Anal Chem, v. 67, p. 393R-97R, 1995.

6. NATHAN, D. M. et al. Translating the A1c assay into estimated average glucose values. Diabetes Care, v. 31, p. 1-6, 2008.

7. MONNIE, L.; COLETTE, C. Glycemic variability: should we and can we prevent it? Diabetes Care, v. 31, suppl. 2, p. S150-S154, 2008.

8. CERIELLO, A.; ESPOSITO, K.; PICONI, L. et al. Oscillating glucose is more deleterious to endothelial function and oxidative stress than mean glucose in normal and type 2 diabetic patients. Diabetes, v. 57, p. 1349-54, 2008. 